\title{
Imaging Evaluation of Intracranial Infections by Computed Tomography and Magnetic Resonance - A Comparative Study of 50 Cases
}

\author{
Hrishikesh Choudhury ${ }^{1}$, Priyanka Priyadarshini Baishya ${ }^{2}$, Tralukya Nandan Sonowal ${ }^{3}$, Diganta Das ${ }^{4}$, Ipsita Das ${ }^{5}$ \\ ${ }^{1}$ Assistant Professor, Department of Radiology, Gauhati Medical College and Hospital, Guwahati, Assam, India. \\ ${ }^{2}$ Assistant Professor, Department of Radiology, Gauhati Medical College and Hospital, Guwahati, Assam, India. \\ ${ }^{3}$ Assistant Professor, Department of Radiology, Gauhati Medical College and Hospital, Guwahati, Assam, India \\ ${ }^{4}$ Assistant Professor, Department of Medicine, Assam Medical College and Hospital, Guwahati, Assam, India. \\ ${ }^{5}$ Registrar, Department of Physiology, Gauhati Medical College and Hospital, Guwahati, Assam, India.
}

\section{ABSTRACT}

\section{BACKGROUND}

Intracranial infections are a common cause of morbidity and mortality, especially in this era of HIV epidemic. Imaging serves as a vital tool in the evaluation of intracranial infections as signs \& symptoms are nonspecific. Both CT and MRI of brain play immense role in the diagnosis \& characterisation of intracranial infective lesions, especially the advanced MRI techniques which can determine the in vivo biochemical nature \& the metabolic spectra of these lesions. The objective of our study is to determine the imaging characteristics, compare the CT \& MRI imaging features of cases of infectious brain lesions referred to the Department of Radiology, GMCH.

\section{METHODS}

After taking proper consent and history, contrast enhanced Computed Tomography \& Magnetic Resonance Imaging of the brain were done in all patients of the study group, who were referred to the Radiology Department, on the basis of clinical signs and symptoms.

\section{RESULTS}

50 cases of intracranial infection were studied and amongst those, males are more commonly affected than females, neuro cysticercosis is the commonest, followed by tuberculosis. Parameters like number \& size of lesions, pattern of meningeal involvement, presence of hydrocephalus, MRS, DWI characteristics of the lesions were evaluated.

\section{CONCLUSIONS}

MRI is more accurate than CT in detecting \& diagnosing intracranial infections, specially the advanced MRI techniques which can even differentiate between pyogenic, fungal \& tubercular abscesses.

\section{KEYWORDS}

Intracranial Infection, Computed Tomography, Magnetic Resonance Imaging, Diffusion Weighted Imaging, Magnetic Resonance Spectroscopy
Corresponding Author:

Dr. Priyanka Priyadarshini Baishya, House No. 53, Tokobari Satra, A. T. Road, Near Hotel Vishwaratna,

Guwahati-781001, Assam, India.

E-mail:

priyankapriyadarshini1986@gmail.com

DOI: $10.14260 / j e m d s / 2019 / 628$

Financial or Other Competing Interests: None.

How to Cite This Article:

Choudhury H, Baishya PP, Sonowal TN, et al. Imaging evaluation of intracranial infections by computed tomography and magnetic resonance. a comparative study of 50 cases. J. Evolution Med. Dent. Sci. 2019;8(38):2891-2896, DOI: $10.14260 /$ jemds $/ 2019 / 628$

Submission 11-05-2019,

Peer Review 04-09-2019,

Acceptance 11-09-2019,

Published 23-09-2019. 


\section{BACKGROUND}

The incidence of intracranial infection is particularly high in developing third world countries like India. It has dramatically increased all over the world especially in the setting of the HIV/ AIDS epidemic, following organ transplantation, as this group of patients are chronically immunosuppressed.(1) There is also increase in the incidence of intracranial infection due to the fact that nowadays due to other immune suppression conditions like post-transplant patients and auto immune diseases treatment. Prompt detection and an accurate diagnosis are paramount as most of these diseases are readily treatable \& if left untreated can lead to significant morbidity \& mortality. The key to this is Neuroimaging.(2) Neuroimaging plays a crucial role in early detection of these conditions and eventually help in guiding and gearing appropriate treatment.

CT and MRI studies are generally the modalities of choice in the evaluation of intracranial infections. Both CT and MRI have excellent delineation of the intracranial pathologies. Especially, the advanced MRI techniques have further aided in early diagnosis and in determining the in vivo biochemical spectra of lesions. CT scan is faster, less expensive, less time consuming, widely available and is usually the first diagnostic modality in the assessment of suspected CNS infections. It helps to delineate the extent of disease, the severity and resultant complications and sequelae and thus helps in narrowing down the differential diagnosis. MRI is a multimodality imaging technique compared to CT scan and is a top notch modality which is inherently superior to CT not only in the detection of CNS infections but in the resolution of numerous diagnostic dilemmas that arise from time to time.(2) MRI also has better spatial resolution and can be used as a problem solving tool in difficult cases. The diagnostic accuracy of MRI has increased manifolds with the advent of MR spectroscopy and diffusion weighted imaging.

We wanted to diagnose and characterise diffuse and focal infectious brain lesions on computed tomography (CT) and magnetic resonance imaging (MRI). We also wanted to correlate CT and MRI imaging findings.

\section{METHODS}

The study was carried out in the Department of Radiology, Gauhati Medical College and Hospital, Guwahati, Assam. The study was designed as a hospital based cross-sectional observational study. 50 cases of clinically suspected intracranial infection, presenting from both indoor and outdoor units of the various departments of G.M.C.H. were taken up for the study. Patients were usually referred from the departments of Medicine, Neurology etc.

Significant clinical history of the referred patients eg: duration, mode of onset of symptoms, intensity of symptoms like headache, vomiting, seizures etc. were taken. The history comprised of chief complaints, duration of illness, occupational history, personal, socio economic history and past history. Both general, systemic and laboratory examinations of the patients were done or reviewed.

\section{CT Imaging}

Positioning- Consent for the examination was taken from the patient or attendant. Patients were scanned in the supine position with their arms by the side of their body. Scans were performed in the axial axis from cephalic to caudal levels, along the canthomeatal line. Care was taken not to give unnecessary radiation exposure to the patients. The machine used is PHILIPS MX16 (16 SLICE CT) scanner.

Scanning- Routine head CT was performed in an axial axis with a 15 to 20-degree angulation of the gantry to the canthomeatal line to decrease radiation to the eyes. Thin slices of $5 \mathrm{~mm}$ with axial reconstruction into $3 \mathrm{~mm}$ were taken at region of interest. Bony algorithm was used in selected cases. Contrast study was done in all patients except those in whom it is contra indicated. Patients were kept on empty stomach for at least $6 \mathrm{hrs}$.

\section{MR Imaging}

The machine used is the SIEMENS TIM AVANTO 1.5 Tesla machine. Before the scans were performed, proper consent was taken. Detailed history of any metallic implant, pacemaker or any foreign body insertion into the body was enquired from the patient or attendants, the procedure was explained to the patient so as to allay any apprehensions. Patient were kept nil orally for at least 4 hours preceding the scan.

Positioning- Patients were positioned supine, head first, placing the head properly in head coil. The patients were positioned as comfortable as possible to minimize movement artefacts.

MR Protocol- Plain with contrast (Gd-DTPA) MR examinations of the brain were performed in all patients. Axial, coronal and sagittal spin-echo (SE) T1W (TR, 450-600 msec; TE, 15-20 msec) and T2W (TR, 2000-3000 msec; TE, 80-100 $\mathrm{msec}$ ), FLAIR pre-contrast images were obtained in all patients. DWI, SWI and MRS studies were performed in selected cases. Gd DTPA-dimeglumine solution was injected IV in a dosage of $0.1 \mathrm{mmol} / \mathrm{kg}$ body weight. Gadopentate dimeglumine enhanced axial (SE) T1W (TR, 450-600 msec; TE, 15-20 msec) images were obtained in all patients. Sagittal and coronal postcontrast TWI were taken in selected cases.

\section{Statistical Analysis}

Descriptive statistical analysis has been carried out in the present study. Results on continuous measurements are presented on Mean SD (Min-Max) and results on categorical measurements are presented in Number (\%). Significance is assessed at $5 \%$ level of significance.

\section{Assumptions on Data}

1. Dependent variables should be normally distributed,

2. Samples drawn from the population should be random.

3. Cases of the samples should be independent.

Chi-square/ Fisher Exact test has been used to find the significance of study parameters on categorical scale between two or more groups. Diagnostic statistics viz. Sensitivity, Specificity, PPV, NPV and Accuracy have been computed to find the correlation of CT and MR findings. 
Sample Size estimation

Proportion Known populations

$\mathrm{n}=[(\mathrm{z} 2 * \mathrm{p} * \mathrm{q})+\mathrm{ME} 2] /[\mathrm{ME} 2+\mathrm{z} 2 * \mathrm{p} * \mathrm{q} / \mathrm{N}]$

Proportion Unknown population

$\mathrm{n}=[(\mathrm{z} 2 * \mathrm{p} * \mathrm{q})+\mathrm{ME} 2] /(\mathrm{ME} 2)$

ME: Standard deviation is the margin of error; measure of

precision and $\mathrm{Z}$ is 1.96 as critical value at $95 \% \mathrm{CI}$.

$S D=\sqrt{\frac{\sum(\mathrm{x}-\bar{x})_{2}}{n-1}}$

\section{Chi-Square Test}

The chi-square test for independence is used to determine the relationship between two variables of a sample. In this context independence means that the two factors are not related. In the chi-square test for independence the degree of freedom is equal to the number of columns in the table minus one multiplied by the number of rows in the table minus one

$$
\chi^{2}=\frac{\sum(O i-E i)^{2}}{E i} \text {. }
$$

Where Oi is observed frequency and Ei is Expected frequency with (n-1) df

Assumptions of Chi-square test- Chi square test, when used with the standard approximation that a chi-square distribution is applicable, has the following assumptions-

- Random sample - A random sampling of the data from a fixed distribution or population.

- Sample size (whole table) - A sample with a sufficiently large size is assumed. If a chi square test is conducted on a sample with a smaller size, then the chi square test will yield an inaccurate inference. The researcher, by using chi square test on small samples, might end up committing a Type II error.

- Expected Cell Count - Adequate expected cell counts. Some require 5 or more, and others require 10 or more. A common rule is 5 or more in all cells of a 2 -by- 2 table, and 5 or more in $80 \%$ of cells in larger tables, but no cells with zero expected count. When this assumption is not met, Fisher Exact test or Yates' correction is applied.

\section{Fisher Exact Test}

The Fisher Exact Test looks at a contingency table which displays how different treatments have produced different outcomes. Its null hypothesis is that treatments do not affect outcomes-- that the two are independent. Reject the null hypothesis (i.e., conclude treatment affects outcome) if $p$ is "small".

$$
2 \times 2 \text { Fisher Exact Test statistic }=\quad \sum p=\frac{(a+b) !(c+d) !(a+c) !(b+d) ! 1}{n !}
$$

The following statistics can be defined

- Sensitivity: probability that a test result will be positive when the disease is present (True positive rate, expressed as a percentage $)=a /(a+b)$.

- Specificity: probability that a test result will be negative when the disease is not present (True negative rate, expressed as a percentage). $=d /(c+d)$.
- Positive predictive value: probability that the disease is present when the test is positive (Expressed as a percentage $).=a /(a+c)$.

- Negative predictive value: probability that the disease is not present when the test is negative (Expressed as a percentage $).=d /(b+d)$.

- Accuracy is the sum of true positive and true negative divided by number of cases.

\section{Statistical Software}

SAS 9.2, SPSS 15.0, Stata 10.1, MedCalc 9.0.1, Systat 12.0 and $\mathrm{R}$ environment Ver.2.11.1 were used for the analysis of the data and Microsoft Word and Excel have been used to generate graphs, tables etc.

\section{RESULTS}

\section{Sex Distribution}

In our study, out of the 50 patients with intracranial infection

\begin{tabular}{|c|c|c|}
\hline Age Groups & No. of Cases & Percentage \\
\hline $10-20$ & 3 & 6 \\
\hline $20-30$ & 11 & 22 \\
\hline $30-40$ & 14 & 28 \\
\hline $41-50$ & 10 & 20 \\
\hline $51-60$ & 7 & 14 \\
\hline $61-70$ & 5 & 10 \\
\hline \multicolumn{3}{|c|}{ Table 1. Age Distribution of Cases } \\
\hline \multicolumn{3}{|c|}{$\begin{array}{l}\text { Maximum numbers of cases in this study were in the } 4^{\text {th }} \text { decade of life followed by } \\
3^{\text {rd }} \text { decade. }\end{array}$} \\
\hline
\end{tabular}
33 were male and 17 were female. Males accounted for $66 \%$ and females accounted for $34 \%$ of the total number of cases.

\begin{tabular}{|c|c|c|}
\hline Signs \& Symptoms & No. of cases & Percentage (\%) \\
\hline Headache & 45 & 90 \\
\hline Vomiting & 40 & 80 \\
\hline Fever & 33 & 66 \\
\hline Seizures & 25 & 50 \\
\hline Neurological deficit & 29 & 58 \\
\hline Neck rigidity & 20 & 40 \\
\hline \multicolumn{2}{|c|}{ Table 2. Common Presenting Symptoms of Patients } \\
\hline $\begin{array}{l}\text { In our study, most of the patients presented with headache followed by vomiting, } \\
\text { fever, seizures etc. }\end{array}$
\end{tabular}

\section{Disease Wise Distribution of Cases}

In our study, neurocysticercosis is the commonest intracranial infection, followed by tuberculosis. Majority of cases were comprised of neurocysticercosis and tuberculosis. Rest of the cases were of Japanese encephalitis, pyogenic abscesses, hydatid cyst etc. An association between neurocysticercosis and Japanese encephalitis was evident as out of the 8 cases of JE, 3 patients showed radiological evidence of NCC. These 3 patients presented with symptoms of encephalitis and were NCC was clinically silent. This is due to the fact that pig serves as a host \& reservoir for both these diseases.

\begin{tabular}{|c|c|c|}
\hline Lesions & No. of Case & $\mathbf{\%}$ \\
\hline Tuberculomas & 12 & 24 \\
\hline Neuro cysticercosis & 18 & 36 \\
\hline Hydatid cyst & 2 & 4 \\
\hline Pyogenic abscesses & 5 & 10 \\
\hline Japanese encephalitis & 8 & 16 \\
\hline Herpes simplex encephalitis & 2 & 4 \\
\hline Toxoplasmosis & 2 & 4 \\
\hline Cryptococcosis & 1 & 2 \\
\hline \multicolumn{2}{|c|}{ Table 3. Distribution of Diseases } \\
\hline
\end{tabular}




\begin{tabular}{|c|c|c|c|c|c|c|c|c|}
\hline 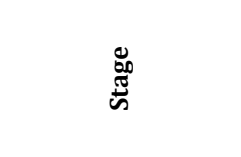 & 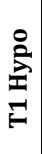 & 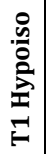 & 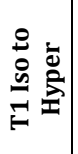 & $\begin{array}{l}\stackrel{2}{2} \\
\stackrel{2}{2} \\
N\end{array}$ & 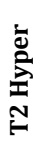 & 总总 & 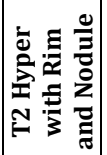 & 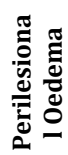 \\
\hline Vesicular (n=2) & 2 & - & - & - & - & 2 & - & 0 \\
\hline Colloid Vesicular $(n=3)$ & & 3 & - & - & - & 2 & 1 & 3 \\
\hline Granular Nodular $(\mathrm{n}=5)$ & 2 & 3 & & - & 2 & 2 & 1 & 5 \\
\hline Nodular Calcified $(\mathrm{n}=2)$ & - & - & 2 & - & - & 2 & - & \\
\hline Various Stages $(\mathrm{n}=6)$ & 3 & 1 & 2 & - & 1 & 2 & 3 & 4 \\
\hline
\end{tabular}

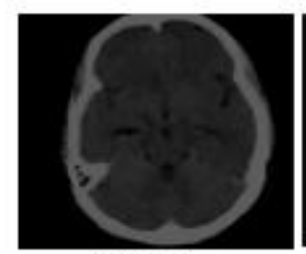

NECT

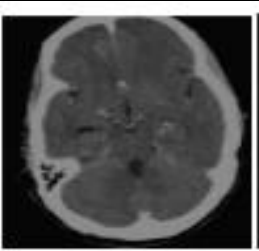

CECT

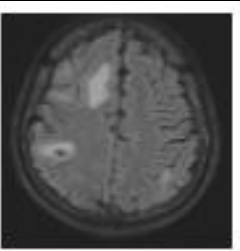

FLAIR
Case 1. 30 yrs. Old Male Patient Presented with Seizures \& Headache for Last 5 Months. CECT \& MRI Brain was done which Revealed NCC. NCCT Scans Shows Oedema in the Right Basifrontal Lobe. Post Contrast Image Shows Peripherally Enhancing Lesion in Right Basifrontal Lobe. Flair Image Shows Lesions in the Right Fronto Parietal Lobe \& Left Parietal Lobe

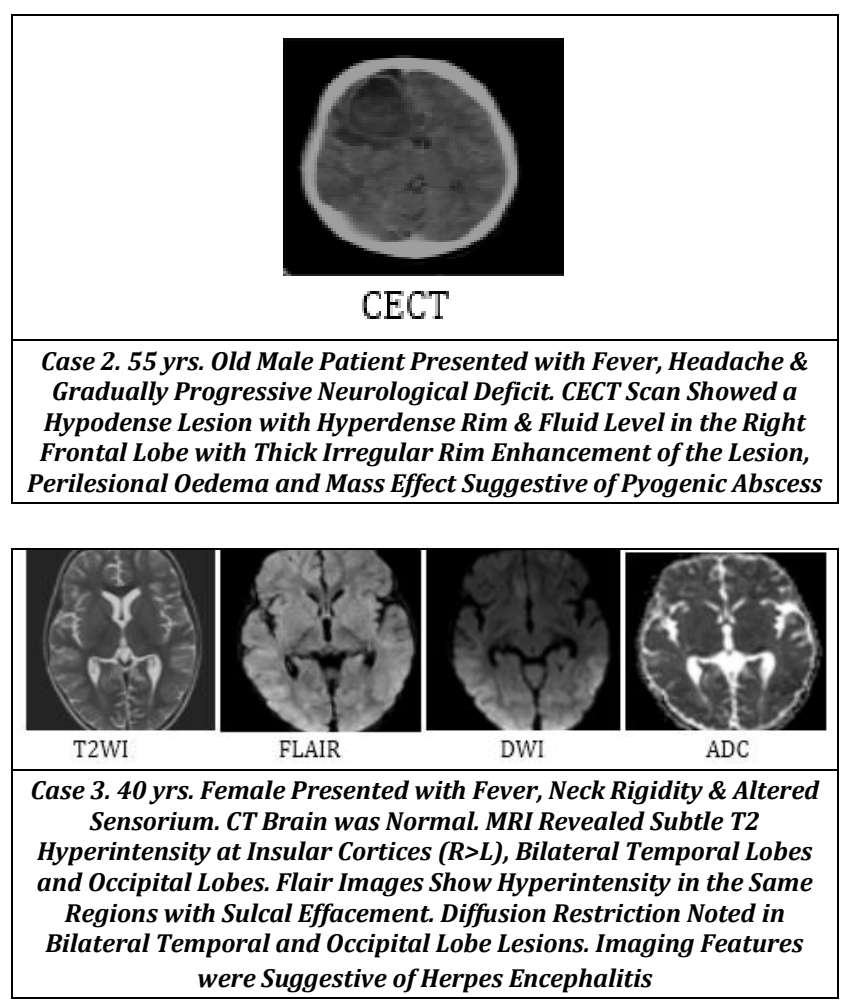

T2WI

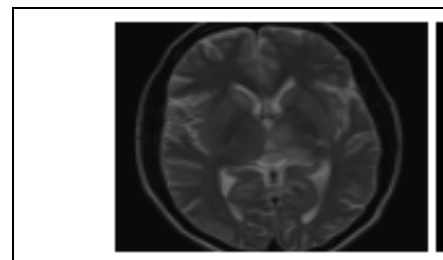

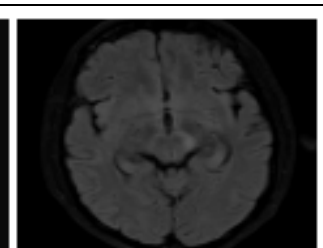

FLAIR
Case 4. 30 yrs. Old Male Patient Presented with Altered Sensorium, Fever, Seizures \& Vomiting. CT Brain was done which was Normal. MRI Brain Revealed T2 Hyperintensity in Left Thalamus, Flair Hyperintensity in Left Thalamus and Substantia NigraFeatures are Suggestive of Japanese Encephalitis

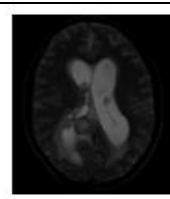

T2WI

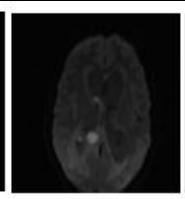

DWI

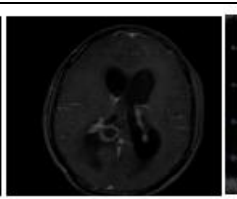

CEMRI

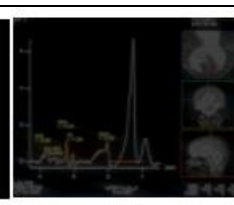

MRS
Case 5. 25 yrs. Old Male Patient Presented with Neurological Deficit, Altered Sensorium, Fever, Vomiting \& Headache. Contrast Enhanced MRI of Brain was done which Revealed T2 Hyperintense Lesion with a Hypointense Rim Appearing Hypointense on Flair in the Central Part Showing Diffusion Restriction with Rim Enhancement on Post Gad Images Involving the Splenium with Perilesional Oedema. On Spectroscopy Lipid Peak is Noticed. Imaging Features were Suggestive of Tuberculoma with Meningitis

\section{DISCUSSION}

Most of the patients in our study were in the $3^{\text {rd }} \& 4^{\text {th }}$ decades of life. This age pattern is similar to the studies done by R. K. Gupta et al and Bahemuka et al $(3,4)$ Headache \& vomiting were common chief complaints followed by fever \& seizures which correlated with other studies.(5)

Neurocysticercosis usually show multiple lesions of similar size. Multiplicity \& similar size of lesions is common in NCC, with perilesional edema in some cases, except in vesicular \& nodular calcified stage. No mass effect is seen in any case. The above characters of the lesions correlated with that described by Zee and co-workers.(6) No diffusion restriction is seen with nonspecific MRS features - like presence of few amino acid peaks. MRI was better in detection of the number and stages of the lesions compared to CT scan.

Tuberculoma usually shows multiple lesions of different size, some may be conglomerated. Nine of the twelve $(75 \%)$ tuberculomas were between $1-3 \mathrm{~cm}$ is size with the rest $3 / 12$ (25\%) being more than $3 \mathrm{~cm}$. Multiple lesions were seen in $8 / 12(67 \%)$ cases. In their study of 46 tuberculomas, Price et al (1984) found 32/46 (70\%) cases between 1 and $3 \mathrm{~cm}$ and multiple lesions in 36/46 (80\%) cases. ${ }^{(6)}$

Most tuberculomas $(10 / 12-85 \%)$ in our study were supratentorial in location with frontal and parietal lobes being involved in $9 / 12(80 \%)$ of cases. The distribution pattern is similar to one in the study undertaken by De Angelis et al.(7) Most tuberculomas were T2 hypointense lesions. T2 hypointense character with MRS at $135 \mathrm{~ms}$ (84\%) showing a well-defined lipid peak at $1.3 \mathrm{ppm}$ is highly (75\%) specific for a tuberculoma in our study. Other MRS features of reduced NAA, increased choline \& presence of lactate is also seen. Diffusion restriction is seen in most cases specially in tubercular abscess. Associated complications are present in $5 / 12(41 \%)$ of cases having obstructive hydrocephalus, abscess and infarct. Concomitant meningitis predominantly basal meningitis is detected in $50 \%$ of cases. MRI could better delineate the extent of lesions, distinguish tuberculoma form tubercular abscess and could also evaluate complications better than CT.

Japanese encephalitis is endemic in this part of the country and outbreaks frequently occur in the month of June and July. In the 8 cases of Japanese encephalitis, serological correlation for JE was done. Preliminary head CT was done in all cases, but only 3 cases showed findings in CT. 


\begin{tabular}{|c|c|c|c|c|c|c|c|c|}
\hline Lesions & $\begin{array}{c}\text { Sites } \\
\text { Involved }\end{array}$ & CT Appearances & T1 WI & T2WI & DWI & MRS & $\begin{array}{c}\text { Contrast } \\
\text { Enhancement }\end{array}$ & Complications \\
\hline Tuberculoma & Grey white junction & $\begin{array}{l}\text { Hypo to isodense } \\
\text { nodular lesion }\end{array}$ & $\begin{array}{c}\text { Hypointense with } \\
+/- \text { faint } \\
\text { peripheral } \\
\text { hyperintensity }\end{array}$ & $\begin{array}{c}\text { Hypo to hyperdense } \\
\text { depending on the } \\
\text { stage }\end{array}$ & $\begin{array}{c}++ \text { depending } \\
\text { on stage }\end{array}$ & $\begin{array}{c}\text { Increased lipid } \\
\text { lactate, choline, } \\
\text { reduced NAA }\end{array}$ & $\begin{array}{l}\text { Nodular or } \\
\text { peripheral } \\
\text { enhancement }\end{array}$ & $\begin{array}{l}\text { Meningitis ++, } \\
\text { hydrocephalus++ }\end{array}$ \\
\hline NCC & $\begin{array}{l}\text { CSF spaces, grey } \\
\text { white junction, } \\
\text { intraventricular }\end{array}$ & $\begin{array}{c}\text { Hypo to isodense } \\
\text { nodular or cystic lesion }\end{array}$ & Hypointense & $\begin{array}{c}\text { Hypo to } \\
\text { hyperintense } \\
\text { depending on the } \\
\text { stage }\end{array}$ & -- & \begin{tabular}{|c|} 
Increased \\
lactate alanine, \\
succinate \& \\
choline \& \\
reduced NAA, \\
creatine \\
\end{tabular} & $\begin{array}{l}\text { Nodular or } \\
\text { peripheral } \\
\text { enhancement }\end{array}$ & Hydrocephalus +/- \\
\hline Hydatid cyst & Cerebral hemispheres & Hypodense cystic lesion & $\begin{array}{c}\text { Hypointense lesion } \\
\text { with isointense } \\
\text { wall }\end{array}$ & $\begin{array}{l}\text { Hyperintense lesion } \\
\text { with hypointense } \\
\text { wall }\end{array}$ & $\begin{array}{c}+/- \text { in the } \\
\text { wall, - in the } \\
\text { internal } \\
\text { contents }\end{array}$ & \begin{tabular}{|c|} 
Increased \\
Pyruvate, \\
alanine \\
Succinate, lipid, \\
lactate
\end{tabular} & $\begin{array}{c}\text { Peripheral } \\
\text { enhancement }\end{array}$ & $\begin{array}{l}\text { Hydrocephalus, } \\
\text { meningitis +/- }\end{array}$ \\
\hline Pyogenic abscess & Cerebral hemispheres & $\begin{array}{l}\text { Hypodense lesion with } \\
\text { perilesional oedema }\end{array}$ & $\begin{array}{c}\text { Hypointense lesion } \\
\text { with irregular } \\
\text { isointense wall } \\
\end{array}$ & $\begin{array}{c}\text { Hyperintense lesion } \\
\text { with hypointense } \\
\text { wall }\end{array}$ & \begin{tabular}{|c|}
+++ in the \\
contents, $+/-$ \\
in the wall \\
\end{tabular} & $\begin{array}{c}\text { Increased } \\
\text { amino acids, }\end{array}$ & $\begin{array}{c}\text { Irregular peripheral } \\
\text { enhancement }\end{array}$ & $\begin{array}{l}\text { Ventriculitis, } \\
\text { Hydrocephalus, } \\
\text { meningitis }\end{array}$ \\
\hline $\begin{array}{l}\text { Japanese } \\
\text { encephalitis }\end{array}$ & $\begin{array}{l}\text { Ventral thalami, } \\
\text { midbrain, cerebral } \\
\text { peduncles }\end{array}$ & $\begin{array}{l}\text { Ill-defined hypodensity } \\
\text { in involved areas }\end{array}$ & $\begin{array}{c}\text { Hypointensity in } \\
\text { involved areas }\end{array}$ & $\begin{array}{l}\text { Hyperintensity in } \\
\text { involved areas }\end{array}$ & variable & $\begin{array}{c}\text { Reduced NAA, } \\
\text { increasing lipid } \\
\text { lactate }\end{array}$ & $\begin{array}{c}\text { +/-Patchy } \\
\text { enhancement }\end{array}$ & $\begin{array}{c}\text { Haemorrhagic } \\
\text { encephalitis, cerebral } \\
\text { oedema }\end{array}$ \\
\hline $\begin{array}{c}\text { Herpes simplex } \\
\text { encephalitis }\end{array}$ & $\begin{array}{l}\text { Temporal lobes, } \\
\text { limbic system, } \\
\text { basifrontal lobes } \\
\text { \&insula }\end{array}$ & $\begin{array}{l}\text { Ill-defined hypodensity } \\
\text { in involved areas }\end{array}$ & $\begin{array}{l}\text { Hypointensity in } \\
\text { involved areas }\end{array}$ & $\begin{array}{l}\text { Hyperintensity in } \\
\text { involved areas }\end{array}$ & $+/-$ & $\begin{array}{c}\text { Reduced NAA, } \\
\text { creatine, } \\
\text { increased } \\
\text { choline; lipid, } \\
\text { lactate if } \\
\text { necrosis is } \\
\text { present } \\
\end{array}$ & $\begin{array}{c}\text { Gyral, patchy or } \\
\text { diffuse enhancement }\end{array}$ & $\begin{array}{c}\text { Necrotising, } \\
\text { haemorrhagic } \\
\text { encephalitis, cerebral } \\
\text { oedema }\end{array}$ \\
\hline toxoplasmosis & $\begin{array}{c}\text { Basal ganglia, thalami } \\
\& \text { corticomedullary } \\
\text { junction }\end{array}$ & $\begin{array}{c}\text { Hypodense areas with } \\
\text { mass effect }\end{array}$ & $\begin{array}{c}\text { Iso to hypointense } \\
\text { lesions, }\end{array}$ & $\begin{array}{l}\text { Iso to hyperintense } \\
\text { lesions, concentric } \\
\text { target sign }\end{array}$ & + & $\begin{array}{c}\text { Reduced NAA, } \\
\text { choline, } \\
\text { creatine } \\
\text { increased lipid, } \\
\text { lactate }\end{array}$ & $\begin{array}{c}\text { Nodular or } \\
\text { peripheral } \\
\text { enhancement }\end{array}$ & Cerebral oedema \\
\hline Cryptococcosis & $\begin{array}{l}\text { Meningeal } \\
\text { involvement, } \\
\text { perivascular spaces, } \\
\text { midbrain, basal } \\
\text { ganglia }\end{array}$ & $\begin{array}{c}\text { Normal/ brain atrophy/ } \\
\text { hydrocephalus/ } \\
\text { hypodense masses }\end{array}$ & Hypointensity & hyperintensity & $+/-$ & & $\begin{array}{l}\text { Leptomeningeal } \\
\text { enhancement, } \\
\text { Nodular or } \\
\text { peripheral } \\
\text { enhancement of } \\
\text { cryptococcoma, }\end{array}$ & hydrocephalus \\
\hline \multicolumn{9}{|c|}{ Table 4. Imaging Characteristics of Diseases } \\
\hline
\end{tabular}

CT scan is not very sensitive or specific in detecting lesions of Japanese encephalitis. MRI is a better modality in suspected cases of Japanese encephalitis. MRI revealed almost similar findings in all cases. The findings included low signal intensity on T1WI in 4 cases (50\%). On T2WI and FLAIR images, increased signal intensities were noted in bilateral thalami ( $100 \%$ cases), substantia nigra ( $63 \%$ cases), basal ganglia ( $25 \%$ cases) and in dorsal pons (12\% cases).

In 5 of the cases there was diffusion restriction. Similar findings were observed by JCW Siu and colleagues which showed lesions involving thalami, substantia nigra and basal ganglia.

Our study had 2 cases of Herpes simplex encephalitis. NECT though not very sensitive in detecting changes of Herpes encephalitis is used as the first modality for evaluation of cases of suspected encephalitis. CT study revealed hypodensities predominantly in bilateral temporal lobes in 1 case \& was reported normal in the other case. MR study revealed similar finding in both cases. The findings included low signal intensity on T1 WI and high signal intensity on T2 WI. The lesions were localized to bilateral temporal lobes, insular cortex and inferior frontal area. There is associated gyral swelling \& diffusion restriction. These features resembled the findings of Herpes simplex encephalitis described in the literature by Demaerel \& Tien et al.(8)

Five patients of pyogenic brain abscess were included in our study. These cases were first subjected to CT scan followed by MRI in those cases in which CT was not conclusive. 2 of the 5 cases (40\%) had a history of chronic otitis media. Supratentorial location is the commonest site. Perilesional edema was seen in all the cases \& significant midline shift was noted in 2 cases. Conglomeration \& satellite abscesses was seen in 3 cases. Obstructive hydrocephalus was present in 2 cases (40\%). These lesions showed irregular thick wall enhancement. Typical pyogenic brain abscess is a large lesion that is hypodense in CT, T1 hypointense (With or without hyperintense rim), T2 hyperintense with hypointense rim, surrounding edema, significant mass effect and associated complications. All cases showed significant central restricted diffusion \&MRS features of increased lactate, lipid, choline with reduced NAA.(9) MRI is superior to CT for imaging in cerebral abscess due to its better spatial resolution and multiparametric technology.

Both the cases of hydatid cyst presented with headache. CT showed a large well-defined hypodense lesion without or with minimal perilesional edema. MRI imaging revealed single large $(>4 \mathrm{~cm})$ cystic lesion with minimally enhancing walls. Diffusion restriction was absent \& MRS features were nonspecific with subtle amino acids. Both these patients had evidence of hydatid disease elsewhere in the body.

There were two cases of toxoplasmosis. Both the patients were immune compromised. These lesions were T2 hypointense, located in the basal ganglia, with moderate peripheral enhancement, patchy diffusion restriction \& nonspecific MRS features. In CT it was not possible to distinguish toxoplasmosis from other ring enhancing lesion. There was 1 case of cryptococcosis. CSF study was already done which suggested cryptococcal infection. CT showed only hydrocephalus. MRI brain revealed meninigo-encephalitis with perivenular inflammation \& multiple enlarged VR spaces. ${ }^{(10)}$ 


\section{CONCLUSIONS}

Even with the monumental inroads made in the field of therapeutics and the advent of newer antimicrobials, CNS infections still remain a significant cause of morbidity and mortality specially in this part of the world. One reason for this is the inadequate percolation of diagnostic services including CT and MRI, to the grassroots. It usually occurs in the adult age group. Headache and vomiting are common symptoms. Neurocysticercosis \& Japanese encephalitis are commoner in this part of the country than the rest of India, owing to common reservoir. Tubercular infection of the CNS remains one of the most common CNS infection throughout India. CT is readily available, less expensive, faster $\&$ is the first diagnostic modality in the assessment of suspected CNS infections. Though not very specific, it is able to diagnose the condition in most of the cases. In those cases where CT is not specific, it helps to delineate the extent of disease, the severity and resultant complications and sequelae and thus helps in narrowing down the differential diagnosis. MRI owing to its inherent superior tissue resolution and multiparametric ability is a more accurate modality in the evaluation of CNS infections. The diagnostic accuracy of MRI has increased manifolds with the advent of MR spectroscopy, perfusion imaging \& diffusion weighted imaging. MRI is far better than CT scan in evaluation of intracranial infection.

\section{REFERENCES}

[1] Schroth G, Kretzschmar K, Gawehn J, et al. Advantage of MRI in the diagnosis of cerebral infections. Neuroradiology 1987;29(2):120-6.

[2] Sze G, Zimmerman RD. The MRI of infections and inflammatory diseases. RCNA 1988;26(4);839-59.

[3] Gupta RK, Jena A, Sharma A, et al. MRI of intracranial tuberculomas. Journal of Comput Assist Tomogr 1988;12(2):280-5.

[4] Bahemuka M, Murungi JH. Tuberculosis of the nervous system. A clinical, radiological and pathological study of 39 consecutive cases in Riyadh, Saudi Arabia. J Neurol Sci 1989;90(1):67-76.

[5] De Castro CC, Hesselink JR. Tuberculosis. Neuroimaging Clin N Am 1991;1:119-39.

[6] Jinkins JR, Gupta R, Chang KH, et al. MRI of Central Nervous System TB. RCNA 1995;33(4):771-86.

[7] Zee CS, Segall HD, Boswell W, et al. MRI of neurocysticercosis. J Comput Assist Tomogr 1988;12(6):927-34.

[8] Price, Danziger. CT in cranial tuberculosis. AJR 1984;130:769-71.

[9] Grand S, Lai ES, Esteve F, et al. In vivo 1H MRS of brain abscesses versus brain tumors. Neurology 1996;47(3):846-8.

[10] Chun CH, Johnson JD, Hofstetter M, et al. Brain abscess. A study of 45 consecutive cases. Medicine 1986;65(5):41531. 